\title{
A Study of Coping Styles and Stress Tolerance in the Caregivers of Schizophrenic Patients
}

\author{
Dr. Altaf Ahmad Malla ${ }^{1}$, Nasir Mohammad Bhat ${ }^{2 *}$, Zahoor Ahmad Wagay ${ }^{3}$
}

\section{ABSTRACT}

This study attempted to take a closer look at the coping styles and stress tolerance of care givers of schizophrenic patients and to determine the relationship between coping styles and stress tolerance of the caregivers of schizophrenic patients. A total number of 70 caregivers were selected using purposive sampling method. The tools used in this study are Life Change Event Inventory and AECOM Coping Scale Questionnaire. Data were cleaned and analyzed by SPSS version 16.00 windows. It is concluded that the caregivers of schizophrenic patients tend to use certain coping styles more than others and this preference lowers the stress experienced. It is also concluded that caregivers of schizophrenic patients are hardier due to the sociocultural expectations imposed on them.

Keywords: Coping Styles, Stress Tolerance, Caregivers of Schizophrenic Patientsl

The chronic burden of caregiving to a patient with schizophrenia is likely to generate negative emotions. With the advent of deinstitutionalization, caregivers have increasingly assumed greater responsibility for the care of their mentally ill relatives, with the consequent negative caregiving experience a likely cause of stress manifested in heightened expressed emotion. Caring for people with psychosis has been associated with subjective burden and loss, depression, distress, reduced quality of life, lower social support. Higher subjective levels of burden and personal stress have been reported by high expressed emotions relatives compared with low expressed emotions relatives. For many carers, frustration, anger, loneliness and despair are common. Bentelspache et al. identified predictors of high expressed emotions among caregivers of relatives with schizophrenia based on the stress-coping model. Caregivers' appraisal of difficult behaviors and dependency were identified as the primary predictor of critical comments and emotional over-involvement, respectively.

The power of gender roles to influence behavior derives not only from their description of typical and desirable behavior but also from their tendency to be relatively consensual and for

\footnotetext{
${ }^{1}$ Registrar Psychiatry, IMHANS Kashmir, J \& K, India

${ }^{2}$ Research Scholar, Dept. of Education, Central University of Kashmir, 170004 - Srinagar, J \& K, India

${ }^{3}$ Clinical Psychologist, Medicine Sans Frontier (MSF), Srinagar, J \& K,India

*Corresponding Author

(c) 2015 I A Malla, N Bhat, Z Wagay; licensee IJIP. This is an Open Access Research distributed under the terms of the Creative Commons Attribution License (http://creativecommons.org/licenses/by/2.0), which permits unrestricted use, distribution, and reproduction in any Medium, provided the original work is properly cited.
} 
people to be aware of this consensus. The ability of gender roles like other social roles to produce role-consistent behavior follows from the overall validity of the assumption that most other people hold these expectations. ${ }^{[1]}$ Because the societal expectations are higher on the women's gender role, often it pressurizes her and pushes her to a corner where she is left with no choice. According to the feminist perspective, the psychological problems that women experience can only be understood in terms of the positions they occupy in the society. ${ }^{[2]}$ Women do not have the same political and economic power that men do, and our society is structured in such a way that this gender-biased hierarchy maintains itself.

Gross $^{[3]}$ cites Tavris that the view that man is the norm and women is the opposite, lesser or deficient one of the three currently competing views regarding what she calls the "mismeasure of women." This is the view that underlies so much psychological research designed to discover why women are not as something (moral, intelligent, rational) as men. Considerable research has revealed that women experience and respond to stress in distinctive ways compared to men. ${ }^{[4]}$ Women's stress response process is both qualitatively and quantitatively different in terms of hormonal profile, activation of the sympathetic, adrenal, medullary and hypothalamic-pituitaryadrenal-cortical response pathways, and in emotional quality. In addition, the nature of women's lives and realities render them at risk for stress-related effects more often than men.

Mental illness weaves a web of doubt, confusion and chaos around the family. Unwittingly, the person with mental illness can dominate the entire family through control, fear or helplessness and incapacity. Instability, separation, divorce and abandonment are frequent family outcomes of mental illness. Bhatia, Tucker and Kapur ${ }^{[5]}$ cited Gopinath and Chaturvedi that, closer the relationship of the carer with the patient, higher the levels of feelings of helplessness and guilt over not being able to do enough for the patient. However, utilization of social support and a sense of mastery over the situation are associated with lower levels of burden and distress. ${ }^{[6]}$ Greater use of problem solving as a coping strategy and less use of denial is a predictor of wellbeing in the family caregivers.

As in many other spheres of life, the impact of mental health problems also show a gender differential.[7] It has been found that while women are required to be the primary carers if their husbands become mentally ill, it was the woman's own families that were responsible for their care if they were to become ill. Therefore, in many instances, when compared with the husbands, it is the wives who are the primary carers. To exercise this additional caretaker responsibility properly, the wife should be mentally healthy. Increased rates of depression and anxiety were found in female caregivers when compared with the female non- caregivers in the community.[8] Also, it has been found that there are significant increases in psychological distress as women adjust to the caregiver role as well as in women who are continuing to provide care. All this distress can no doubt negatively affect the wellbeing of women. 


\section{AIM}

The aim of this study was to examine coping styles and stress tolerance of care givers of schizophrenic patients and to determine correlations between coping styles and stress tolerance of the caregivers of schizophrenic patients.

\section{MATERIALS AND METHODS}

The present study has a non-experimental or passive, observational design, which includes neither manipulation of the independent variables nor random assignment of participants.

\section{Sample}

The sample consisted of the caregivers whose patients were suffering from schizophrenia. The sample consisted of 70 caregivers both male and female whose age ranged from 20 to 45 years, the mean age being 32.5 years. The educational qualification of the subject ranged from class 10 to graduate degree.

\section{Inclusion criteria}

a. The patients suffered from schizophrenia.

b. The patients had a history of being treated for at least 6 months.

c. The caregivers were living with the subjects for at least 1 year.

\section{Exclusion criteria}

a. The mental illness in the caregivers of the subjects due to drugs, specific organic syndromes or a general medical condition.

b. The mentally ill caregivers of the subjects who were asymptomatic during the period of the study.

The sample was drawn from the Institute of Mental Health and Neuroscience (IMHANS), Srinagar from the outpatient department and inpatient group of the hospital. The diagnoses of the mental illness in the patients were made by the psychiatrist according to DSM-5and ICD-10 criteria.

\section{Assessment Tools}

\section{LIFE CHANGE EVENTS INVENTORY}

A presumptive stressful events scale was developed by Singh et al. in 1981 on the lines of the social readjustments rating scale developed by Holmes and Rahe, and it was modified to suit the South Indian culture by adding 14 new items in 1984 by Radhakrishnan, Joseph and Varghese, which later was adapted to Malayalam by Paul and Moorthy in 1992. The subject is required to presume him/herself to be in the situation described by the items and rate each item on a 5-point scale. How each event is perceived reveals the subject's stress tolerance. Higher the stress score, lower the stress tolerance.

\section{AECOM COPING SCALE}

The Albert Einstein College of Medicine (AECOM) coping style questionnaire was developed by Plutchik, Hope and Conte (1989), which consists of 87 items, each rated by the subject on a 
4-point scale, ranging from "never” to “often”, weighed from zero to three. This model assumes that there are eight basic coping styles, as defined by the author:

Suppression - Avoiding the problem or the situation Succorance - Asking others for help

Replacement - Dealing with problems or finding alternate solutions

Blame - Blaming others or the system for his/her problems

Substitutions - Engaging in tension-reducing activities like sports

Mapping - Collecting information about the situation or the problems

Reversal - Acting the opposite of the way he/she feels Minimization - Minimizing the importance of the problem or solution

Sociodemographic data like religion, duration of marriage, chronicity of the illness, age, socioeconomic status and employment were collected through a personal information schedule.

\section{Statistical analysis}

Product moment correlation is used to determine the extent of the relationship between the variables. Data were cleaned and analyzed by SPSS version 16.00 windows

\section{RESULTS AND DISCUSSION}

Table 1: Stress tolerance (stress score)

\begin{tabular}{|c|c|c|c|c|c|c|c|c|c|}
\hline $\begin{array}{l}\frac{\mathscr{U}}{\pi} \\
\frac{\pi}{\pi} \\
\frac{\pi}{\pi} \\
>\end{array}$ & 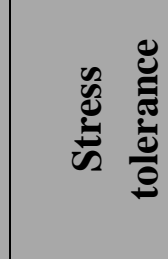 & 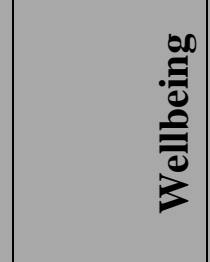 & 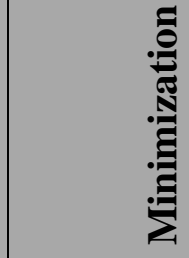 & 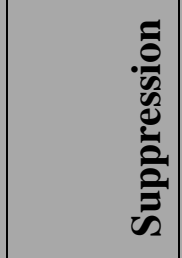 & 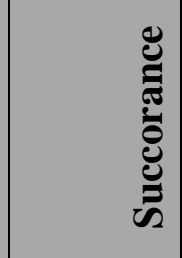 & 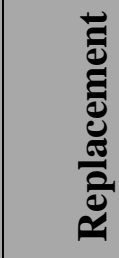 & 咅 & م & 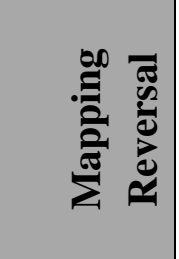 \\
\hline Minimization & -0.372 & 0.275 & & & & & & & \\
\hline Suppression & -0.394 & -0.008 & $0.327 * *$ & & & & & & \\
\hline Succorrance & 0.115 & -0.130 & -0.033 & -0.026 & & & & & \\
\hline Replacement & $-0.206 *$ & 0.070 & 0.056 & 0.161 & $0.332 * * *$ & & & & \\
\hline Blame & 0.135 & -0.128 & 0.097 & $0.381 * * *$ & 0.130 & 0.0727 & & & \\
\hline Substitution & $0.455^{* * *}$ & -0.185 & -0.164 & -0.125 & $0.291 * *$ & 0.193 & $0.309 * *$ & & \\
\hline Mapping & $-0.339 * *$ & 0.112 & $0.373 * * *$ & $0.222^{*}$ & 0.001 & 0.056 & $0.262 * *$ & $-0.213^{*}$ & \\
\hline Reversal & 0.011 & 0.108 & $0.250^{*}$ & $0.278 * *$ & -0.055 & 0.021 & $0.471^{* * *}$ & $0.260 * *$ & $0.351 * * *$ \\
\hline $0.05 ; * * 1$ & $01 ; *$ & 0.001 & & & & & & & \\
\hline
\end{tabular}

From Table 1, it can be seen that stress tolerance has a significant positive correlation of 0.455 with the coping style substitution and a significant negative correlation with the coping styles replacement and mapping (-0.206 and -0.338), respectively. The coping style minimization correlated positively with suppression (0.327), mapping (0.373) and reversal (0.250). Suppression is positively correlated with the use of blame (0.381), mapping (0.223) and reversal 
(0.278). Succorance is positively correlated with replacement and substitution. Blame has a significant positive correlation with substitution, mapping and reversal $(0.309,0.262$ and 0.472 , respectively). Substitution shows a negatively significant correlation with mapping (-0.213) and a significant positive correlation with reversal (0.260). Finally, mapping shows a highly significant positive correlation with reversal (0.351).

Stress tolerance has a highly significant negative correlation with minimization, suppression, replacement and mapping in wives of the mentally ill. As stress increases, use of minimization decreases. As obvious, reducing the importance of the problem does not make the problem go away. Rather, such minimizing can be detrimental for the wife who employs it as well as for the whole family. The same is also true for the coping style suppression. Avoiding the problem can be as bad as minimizing it.

Replacement is not used by the caregivers of the mentally ill, although one might expect them to use it. Women react to stress in an emotional manner, and this heightened emotional arousal may adversely affect their logical thinking and reappraisal skills. Here, however, there is a high significant positive correlation of stress with substitution. This seems to suggest that, probably, replacement gives way to substitution. Women employ more of prosocial activities like tending and befriending to reduce their stress. This sharing with others may result in new ideas or solutions in dealing with the problem.

The coping style minimization has a highly significant positive correlation to mapping, suppression and reversal. Caregivers may be using mapping to selectively gather information regarding the illness, its course, treatment and management. If the problem attached to the stressor is decreased, then the caregivers can very well engage in reversal, where they can act lightly on a serious problem. Although this is a dysfunctional coping style, in this context, it reduces the stress experienced by the women spouses.

From Table 1, it can be seen that suppression has a highly significant positive correlation with blame, mapping and reversal. Using of suppression results in blame, which is placed on a third person, situation or event thus helping the wife to be psychologically non-accountable to her husband's mental illness and subsequent problems arising from it. Mapping could be as explained before - an attempt to collect only those information that may substantiate the use of blame and suppression. In this context, mapping and blame may also enhance the use of reversal, where the wives act the opposite of what they really feel

There is a highly significant positive correlation of succorance with replacement and substitution. Help seeking would no doubt help the to generate alternate solutions just not to the 
problem at hand but also to the other problems arising from the original ones. A natural fall-out of help-seeking behavior is befriending and ventilating. This, in turn, enhances replacement.

Coping style blame has a highly significant positive correlation with reversal, substitution and mapping. This suggests that the blaming style of coping probably results in the active searching of the information that will justify the use of blame. Once blame is directed to an outside element, wives will also feel emotionally more comfortable to handle the situation by employing reversal. Substitution is probably used to justify blame. Also, substitution, by the virtue of its ventilation effect, helps the individual to relieve any guilt they may feel because of using blame, mapping or reversal. It is noteworthy that although, in itself, mapping is a positive coping style, at times it could also generate feelings of guilt.

Substitution has a significantly negative correlation with mapping and a significantly positive correlation with reversal. Substitution involves tension-reducing physical or verbal activities. Females with their multiple roles, given a chance, will choose ventilation verbally as a coping technique to draw comfort from others. With most of their energies spent in trying to hold the fort together, there is less chance of indulging in active mapping. Any mapping that will happen will be in a therapeutic context. Where the coping style reversal is concerned, substitution may help to resolve any emotional conflict, resentment or bitterness that wives may feel toward their husbands and their illness. Thus, substitution may help the wives to act more tolerant with their sick spouses even though they may feel otherwise.

Mapping bears a highly significant positive correlation with reversal. Generally, although gathering information is very helpful, it may at times dish out unsavory facts as well. It could be particularly bad when it involves one's husband and his illness. This may give rise to a host of negative feelings from the wife's part, which she would have to mask or suppress because it is at variance with her role and societal expectations. Thus, reversal happens.

\section{CONCLUSION}

The stress tolerance had a significant positive correlation with the coping style substitution and a significant negative correlation with the coping styles replacement and mapping respectively. The coping style minimization correlated positively with suppression mapping and reversal. Suppression is positively correlated with the use of blame , mapping and reversal. Succorance was positively correlated with replacement and substitution. Blame had a significant positive correlation with substitution, mapping and reversal. Substitution shows a negatively significant correlation with mapping and a significant positive correlation with reversal. Finally, mapping showed a highly significant positive correlation with reversal. 
Stress tolerance had a highly significant negative correlation with minimization, suppression, replacement and mapping in caregivers of the schizophrenic patients. As stress increases, use of minimization decreases. As obvious, reducing the importance of the problem does not make the problem go away. Rather, such minimizing can be detrimental for the wife who employs it as well as for the whole family. The same is also true for the coping style suppression. Avoiding the problem can be as bad as minimizing it. There was a highly significant positive correlation of succorance with replacement and substitution. Help seeking would no doubt help the caregivers to generate alternate solutions just not to the problem at hand but also to the other problems arising from the original ones. A natural fall-out of help-seeking behavior is befriending and ventilating. This, in turn, enhances replacement.

Coping style blame had a highly significant positive correlation with reversal, substitution and mapping. This suggests that the blaming style of coping probably results in the active searching of the information that will justify the use of blame. Once blame is directed to an outside element, caregivers will also feel emotionally more comfortable to handle the situation by employing reversal. Substitution is probably used to justify blame. Also, substitution, by the virtue of its ventilation effect, helps the individual to relieve any guilt they may feel because of using blame, mapping or reversal. It is noteworthy that although, in itself, mapping is a positive coping style, at times it could also generate feelings of guilt.

Mapping beared a highly significant positive correlation with reversal. Generally, although gathering information is very helpful, it may at times dish out unsavory facts as well. A noteworthy finding that has emerged is that the coping styles, mapping and reversal are employed simultaneously by the sample to the extent of the formation of a dyad.

\section{REFERENCES}

1. Eagly AH. Gender roles. In: Kazdin AE, editor. Encyclopedia of Psychology. Vol. 3. United States of America: APA and Oxford University Press Inc; 2000. p. 448-53.

2. Peterson C. Psychology of Abnormality. United States of America: Harcourt, Brace and Company; 1996.

3. Gross R. Themes, Issues and Debates in Psychology. Great Britain: Hodder and Stoughton Educational; 1997.

4. Helgeson VS. Psychology of Gender. New Delhi: Dorling Kindersley Pvt. Ltd.; 2006.

5. Bhatia S, Tucker V, Kapur G. Assessment of burden experienced by caregivers of patients suffering from schizophrenia. J Pers Clin Stud 2003;19:77-88.

6. Budd RJ, Oles G, Hughes IC. The relationship between coping styles and burden in the carers of relatives with schizophrenia. Acta Psychiatr Scand 1998;98:304-9. 
7. Thara R, Patel V. Women's Mental Health: A Public Health Concern. Regional Health Forum, WHO South-East Asia Region. Available from: http://www.whosea.org [last cited on 2001].

8. Geller PA, Graf MC, Dyson Washington F. Women's health psychology. In: Nezu AM, Christine, Magath, Nezu, Geller PM, editors. The Health Psychology Handbook. London: Sage Publication, Inc.; 2003. p. 513-44.

9. Sareena NP, Anita R. Personality, stress tolerance, and wellbeing of women with physical disabilities.Kerala: Unpublished Doctoral Thesis, Department of Psychology, University of Calicut; 2004.

10. Kuruvila J. A study into the job related stress among nurses in relation to locus of control, organizational climate and life change events. Kerala: Unpublished Doctoral Thesis, Department of Psychology, University of Calicut; 1991.

11. Shanty KJ, Anita R. Psychosocial analysis of marital problems. Kerala: Unpublished Doctoral Thesis, Department of Psychology, University of Calicut; 2006.

12. Verma SK, Verma A. PGI General Wellbeing Measure. Lucknow: Ankur Psychological Agency; 1989.

13. Hammen C. Mood disorders. In: Stricker G, Widiger T, editors. Handbook of Psychology, Clinical Psychology. Vol. 8. United States of America: John Wiley and Sons, Inc.; 2003. p. 93-118.

14. Plutchick R, Conte HR. Measuring emotions and the derivatives of the emotions: Personality traits, ego defenses and coping styles. In: Wetzler S, Kats MN, editors. Contemporary Approaches to Psychological Assessment. New York: Brunner Maze; 1989. p. 239-269. 